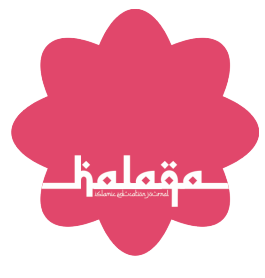

OPEN ACCESS ISSN 2503-5045 (online) ISSN 1412-9302 (print)

Edited by:

Eni Fariyatul Fahyuni

Reviewed by:

Imron Mustofa

${ }^{*}$ Correspondence:

Junaidi Junaidi

Jun_achenk@yahoo.com

Received: 5 Oktober 2020 Accepted: 17 Oktober 2020 Published: 25 Oktober 2020

Citation:

Junaidi J, Dinata KB and Darwanto $D$ (2020) Evaluation and Analysis of

Baitul Arqam on the Morals and Performance of Lecturers and Employees of the University of Muhammadiyah Kota Bumi. Halaqa. 4:2.

doi: 10.21070/halaqa.v4i2.1015

\section{Evaluation and Analysis of Baitul Arqam on the Morals and Performance of Lecturers and Employees of the University of Muhammadiyah Kota Bumi}

\section{Evaluasi dan Analisis Baitul Arqam terhadap Akhlak dan Kinerja Dosen dan Karyawan Universitas Muhammadiyah Kotabumi}

\author{
Junaidi Junaidi*, Karsoni Berta Dinata, Darwanto Darwanto \\ Fakultas Keguruan dan IImu Pendidikan, Universitas Muhammadiyah Kotabumi, Indonesia
}

The aim of this study is as basis for making policies and strategies that need to be taken to improve the quality of Baitul Arqam Program going forward. Baitul Arqam program that has been carried out so far has never been seen in measurable terms. There are three research designs in this study, namely 1) descriptive-qualitative research design, 2) survey research design and 3) CIPP evaluation research design. The result of this study are based on the result of the analysis of the questionnaire and interview, it can be concluded that the lecturers and employees who have participated in Baitul Arqam activities have good morals and high performance. Based on the result of the evaluation it can be concluded that, 1) Baitul arqam material should be made into one book and distributed to participants, 2) The material should also discuss matters related to prayer, organizing bodies, and other worship in accordance with the guidance of HPT, 3) The video interesting learning so that participants are more interested and focused, 4) Every lecturer and employee who has not yet followed the Baitul Arqam must participate in the activity, 5) There is a pre-test and post-test to measure the success of the participants, 6) the mandatory requirements of participants are declared to pass if they take Fathul Quthub and Tahajud Prayers, and follow the material for each session at a minimum $75 \%$.

Keywords: Baitul Arqam, Morals Values, Performance

Tujuan dari penelitian ini adalah sebagai dasar untuk membuat kebijakan dan strategi yang perlu diambil untuk meningkatkan kualitas Program Baitul Arqam ke depan. Program Baitul Arqam yang selama ini dijalankan tidak pernah terlihat secara terukur. Ada tiga desain penelitian dalam penelitian ini, yaitu 1) desain penelitian deskriptif-kualitatif, 2) desain penelitian survei dan 3) desain penelitian evaluasi CIPP. Hasil penelitian ini berdasarkan hasil analisis kuesioner dan wawancara, dapat disimpulkan bahwa dosen dan karyawan yang mengikuti kegiatan Baitul Arqam memiliki akhlak yang baik dan kinerja 
yang tinggi. Berdasarkan hasil evaluasi dapat disimpulkan bahwa, 1) Materi baitul arqam harus dibuat menjadi satu buku dan dibagikan kepada peserta, 2) Materi juga membahas hal-hal yang berkaitan dengan shalat, badan penyelenggara, dan ibadah lainnya sesuai dengan Pembinaan HPT, 3) Video pembelajaran menarik agar peserta lebih tertarik dan fokus, 4) Setiap dosen dan karyawan yang belum mengikuti Baitul Arqam wajib mengikuti kegiatan, 5) Terdapat pre-test dan post -Tes untuk mengukur keberhasilan peserta, 6) persyaratan wajib peserta dinyatakan lulus jika melaksanakan Shalat Fathul Quthub dan Tahajud, serta mengikuti materi tiap sesinya minimal $75 \%$.

Kata Kunci: Baitul Arqam, Moral Values, Performance 


\section{PENDAHULUAN}

Mengacu kepada salah satu misi STKIP dan STIH Muhammadiyah Kotabumi yaitu meningkatkan partisipasi dan memperkuat peran institusi sebagai pusat pengaderan Muhammadiyah dalam rangka pembinaan dan pengembangan Alislam dan Kemuhammadiyahan serta mencerdaskan umat, STKIP dan STIH Muhammadiyah bekerjasama dengan Majelis Pendidikan kader (MPK) Pimpinan Daerah Muhammadiyah (PDM) Kabupaten Lampung Utara berkomitmen untuk secara rutin mengadakan program Baitul Arqam bagi seluruh civitas akademika di lingkungan STKIP dan STIH Muhammadiyah Kotabumi. Harapan dilaksanakan Program Baitul arqam adalah semakin tumbuhnya pemahaman yang mendalam bagi Dosen dan karyawan di Lingkungan STKIP dan STIH Muhammadiyah Kotabumi tentang Muhammadiyah. Refleksi dari pemahaman tersebut akan tampak dalam bentuk Penerapan nilai-nilai akhlak dan semakin meningkatnya kinerja Dosen dan karyawan.

Secara bahasa Baitul Arqam berasal dari kata bait (rumah) dan Arqam yang diambil dari Arqam bin Abil arqam, seorang Pemuda yang termasuk kedalam kelompok yang pertama kali masuk islam di zaman Rasulullah. Jadi Baitul Arqam adalah rumahnya Arqam. Dari Rumah Arqam Inilah Rasulullah membina para sahabat dimasa awal perjuangannya. Terinspirasi dari pengkaderan yang dilakukan oleh Rasulullah, muhammadiyah juga melakukan pengkaderan dengan program yang bernama Baitul Arqam. Jadi Baitul Arqam merupakan suatu wadah pengkaderan dipersyarikatan Muhammadiyah. Tujuannya adalah agar terbentuknya kader muhammadiyah yang beriwa islam berkemajuan serta mempunyai integritas dan kompetensi untuk berperan dalam persyrikatan kehidupan umat, bangsa dan konteks global. Mengutip pesan dari KH. AR Fachrudin yakni " kyai Ahmad Dahlan mendirikan Muhammadiyah bukan sekedar untuk memperbanyak sekolah dan perguruan tinggi, bukan pula sekedar untuk memperbanyak rumah sakit, rumah yatim, dan balai pengobatan, tetapi Kyai mendirikan muhammadiyah untuk menegakan dan menjunjung tinggi agama islam, sehingga sekurang-kurangnya manusia indonesia dapat mewujudkan masyarakat utama, adil makmur berjalan menurut garis yang dirihoi oleh Allah". Oleh karena itu, Perguruan tinggi muhammadiyah merupakan sebuah sarana untuk mencetak kaderkader muhammadiyah yang mampu memahami Islam secara mendalam yang berbuah kepada penerapan akhlak dalam kehidupan kampus, serta bersikap profesional dalam bekerja.

Program Baitul Arqam yang telah dijalankan selama ini, belum pernah dilihat secara terukur mengenai dampaknya terhadap penerapan nilai-nilai akhlak dan kinerja dosen dan karyawan dalam kehidupan civitas akademika di lingkungan kampus STKIP dan STIH Muhammadiyah Kotabumi. Dampak terhadap penerapan nilai-nilai akhlak akan diukur dengan melihat indikator-indikator akhlak yang telah diterapkan. Selanjutnya dampak terhadap kinerja akan diukur dengan melihat tingkat kepuasan terhadap kinerja dosen dan karyawan. Selain itu juga akan dilihat dengan membandingkan kinerja sebelum mengikuti pelatihan dan sesudah pelatihan. Selain itu, perlu dipertimbangkan bahwa Program Baitul Arqam merupakan wujud tindakan pengkaderan yang akan menentukan kelangsungan dan kemajuan muhammadiyah di masa yang akan datang. Oleh karena perlu dilakukan evaluasi untuk melihat tingkat keberhasilan program tersebut. Menurut Arikunto evaluasi program adalah kegiatan untuk mengetahui seberapa tinggi tingkat keberhasilan dari kegiatan yang direncanakan. Model evaluasi yang dilakukan mengacu kepada model yang dikembangkan oleh Stufflebeam yang dikenal dengan CIPP Evaluation model. CIPP merupakan singkatan dari Contex, Input, Process and product.

Dalam pandangan islam manusia terdiri dari tiga unsur yaitu, nafs amarah, nafs lawwamah, dan nafs mutmainah. Ketiganya merupakan unsur hidup yang ada dalam manusia yangkan tumbuh berkembang seiring perjalanan dan pengalaman hidup manusia. Ada empat hal yang harus ada apabila seseorang ingin dikatakan berakhlak yaitu (1) perbuatan yang baik atau buruk (2) kemampuan melakukan perbuatan (3) kesadaran akan perbuatan itu (4) kondisi jiwa yang membuat yang membuat cenderung melakukan perbuatan baik atau buruk. Penanaman nilai-nilai akhlak salah satunya ditentukan oleh faktor yang berasal dari luar, yaitu kondisi lingkunganya. Faktor lingkungan memberikan pengaruh yang kuat terhadap penanaman suatu nilai-nilai kebaikan (Faizal, dkk) . Faktor lingkungan dapat berupa suatu program yang dibuat sedemikian rupa sehingga mampu mengoptimalisasi penanaman suatu nilai tertentu. Program tersebut dapat berupa pelatihan, sosialisasi, dan pembelajaran. Penanaman nilai-nilai akhlak bagi dosen dan staf perguruan tinggi muhammadiyah salah satunya melalui program baitul arqam. Dalam penelitian Nursikin (2019) indikator untuk melihat nilai-nilai akhlak dapat dilihat dari gaya bahasa, cara berpakaian, pelaksanaan nilai-nilai agama dalam konteks akhlak.

Penelitian terkait evaluasi Baitul Arqam telah dilakukan oleh beberapa peneliti sebelumnya. Penelitian yang dilakukan oleh Kartini (2017) tentang Evaluasi Program Baitul Arqam diperoleh hasil penelitian yakni berdasarkan analisis evaluasi baik dari sisi context, input, process, dan product pada Baitul Arqam bagi karyawan di Universitas Muhammadiyah Palangkaraya termasuk kategori baik. Artinya bahwa program ini dapat dilanjutkan dengan perbaikan. Hasil dari penelitian Nurul Hikmah Kartini memberikan inspirasi untuk mengevaluasi Program Baitul Arqam di STKIP dan STIH Muhammadiyah Kotabumi. Kamipun memperluas variabel penelitian dengan melihat dampak penelitian terhadap penerapan nilai-nilai akhlak dan kinerja tidak hanya karyawan tetapi juga dosen di lingkungan STKIP dan STIH Muhammadiyah Kotabumi.

\section{Baitul Arqom}

Baitul Arqom berasal dari kata bait atau arqam. Kata arqam ini berasal dari nama pemuda Arqam bin Abil Arqam yang per- 
tama kali masuk Islam, Baitul Arqam itu artinya rumah Arqam sinonim dari baitul adalah darun yang artinya rumah tempat kembali. Jadi baitul arqam merupakan salah satu kegiatan yang biasa dipakai oleh Muhammadiyah untuk memberikan suatu wawasan dan pengetahuan dan memberikan semangat baru kepada para warga muhammadiyah. Kaderisasi merupakan program dan kegiatan Muhammadiyah yang tidak akan pernah kunjung selesai (never ending job). Di samping itu pelaksanaan misi dan program kerja persyarikatan membutuhkan peran dan fungsi kader yang kompeten, militan, amanah, dan istiqamah. Sebagai sistem, tujuan perkaderan Muhammadiyah berarah pada visi di depan dan berpijak pada misi yang diemban dalam proses dinamisasi pelaksanaan perkaderan yang sistemik, koordinatif, dan berkesinambungan. Dengan alur pertimbangan seperti itu maka rumusan visi dan misi perkaderan Muhammadiyah adalah sebagai berikut.

Visi: kader Muhammadiyah paripurna untuk mewujudkan masyarakat Islam yang sebenar-benarnya. Adapun misimisinya antara lain: mengintensifkan peneguhan ideology Muhammadiyah di seluruh lini persyarikatan, ortom, dan AUM; menyinambungkan pewarisan nilai-nilai bermuhammadiyah; dan mengoptimalkan revitalisasi kader. Anshori (2017) . Kegiatan Baitul Arqom yang diselenggaran oleh PPPAIK (Pusat Pengembangan Pendidikan Al-Islam dan kemuhammadiyahan) STKIP Muhammadiyah dan PPPAIK STIH Muhammadiyah Kotabumi merupakan kerjasama Perguruan Tinggi Muhammadiyah (PTM) dengan Majelis Pendidikan Kader MPK Pimpinan Daerah Muhammadiyah Lampung Utara. PPPAIK membina dan mengembangkan keislaman di kalangan dosen dan karyawan dan mahasiswa bertujuan untuk meningkatkan kualitas dosen, karyawan dan mahasiswa di bidang Al-Islam dan kemuhammadiyahan maka dari itu dibuatlah program pengkaderan yang dinamakan Baitul Arqam. Pelaksanaan Baitul Arqam Bagi Karyawan dan Dosen di STKIP Muhammadiyah dan STIH Muhammadiyah baru dimulai sejak tahun 2018 yang dilakukan pada bulan September 2018 dan pada bulan Desember 2018.

\section{Nilai-nilai Akhlak}

Akhlak menurut etimologis adalah perkataan "akhlaq" berasal dari bahasa Arab jama" dari "khuluqun" yang menurut loghat diartikan: budi pekerti, perangai, tingkah laku atau tabiat. Kalimat tersebut mengandung segi-segi persesuaian dengan perkataan "khalqun" yang berarti: kejadian, serta erat hubungannya dengan "khaliq" yang berarti pencipta, dan "makhluq" yang berarti: yang diciptakan Hamzah (1998). Perumusan pengertian akhlak timbul sebagai media yang memungkinkan adanya hubungan baik antara khaliq dengan makhluk. Secara terminologi, kata akhlak mempunyai beberapa pengertian, diantaranya;

a) Ibnu Maskawaih memberikan definisi sebagai berikut:"Keadaan jiwa seseorang yang mendorongnya untuk melakukan perbuatan-perbuatan tanpa melalui pertimbangan pikiran (lebih dahulu)." Mustofa (2005); b) Imam al-ghazali berpendapat bahwa"Akhlak adalah sifat yang tertanam dalam jiwa yang menimbulkan perbuatan-perbuatan dengan gampang dan mudah, tanpa memerlukan pemikiran dan pertimbangan."( Yunahar, 1999: 2); c) Ahmad Amin memberikan definisi, bahwa yang disebut akhlak ialah " kebiasaan kehendak". Berarti bahwa kehendak itu bila membiasakan sesuatu maka kebiasaannya itu disebut akhlak. Dan bila kehendak itu membiasakan memberi, kebiasaan kehendak ini ialah akhlak dermawan."Akhlak adalah sifat yang tertanam dalam jiwa yang menimbulkan perbuatan-perbuatan dengan gampang dan mudah, tanpa memerlukan pemikiran dan pertimbangan." Yunahar (1999)

Dari beberapa definisi di atas dapat disimpulkan bahwa akhlak merupakan sifat yang tertanam dalam jiwa manusia kemudian muncul secara spontan apabila diperlukan untuk melakukan perbuatan atau berkehendak tanpa adanya dorongan dari luar.

\section{Kinerja Dosen dan Karyawan}

Kinerja adalah sebuah kata dalam bahasa indonesia dari kata dasar "kerja" yang menerjemahkan kata dari bahasa asing prestasi. Bisa pula berarti berarti hasil kerja. Kinerja dalam organisasi merupakan jawaban dari berhasil atau tidaknya tujuan organisasi yang telah ditetapkan. Para atasan atau pimpinan sering tidak memperhatikan kecuali sudah sangat buruk atau segala sesuatu jadi jserba salah. Terkadang pimpinan tidak mengetahui betapa buruknya kinerja telah merosot sehingga institusi menghadapi krisis yang serius. Kesan-kesan buruk organisasi yang mendalam berakibat adanya tandatanda adanya kinerja yang merosot. Prawirosentono (2012 :120) menyatakan bahwa kinerja atau performance adalah hasil kerja yang dapat dicapai oleh seseorang atau sekelompok orang dalam suatu organisasi, sesuai dengan tanggung jawab dan wewenang masing-masing dalam upaya mencapai tujun organisasi. Terdapat hubungan yang erat antara kinerja perorangan dan kinerja organisasi, dengan kata lain bila kinerja karyawan baik maka kemungkinan kinerja organisasi juga akan baik. Kinerja Perorangan dalam suatu organisasi merupakan roda penggerak dari suatu organisasi.

Arifin et al. (2015) menyebutkan kinerja, atau performance adalah hasil kerja yang dapat dicapai oleh seseorang atau sekelompok orang dalam suatu organisasi, sesuai dengan tanggung jawab dan wewenang masing-masing dalam upaya mencapai tujuan Organisasi. Sejalan dengan hal ini, Veizal Rivai (2004:309) mengemukakan kinerja merupakan perilaku yang nyata yang ditampilkan setiap orang sebagai prestasi kerja yang dihasilkan oleh karyawan sesuai dengan perannya dalam institusi. Mengacu kepada Undang-undang no 12 tahun 2012 menyatakan bahwa Dosen adalah Pendidik profesional dan ilmuwan dengan tugas utama mentransformasikan, mengembangkan, dan menyebarluaskan ilmu pengetahuan, teknologi, dan seni melalui pendidikan, penelitian dan pengabdian kepada masyarakat. Karyawan dalam penelitian ini adalah tenaga pendidik yang meliputi Staf akdemik, 
Bagian Umum, Perpustakaan, Kebersihan, dan Keamanan. Berdasarkan pendapat para ahli di atas disimpulkan kinerja dosen dan karyawan merupakan hasil atau prestasi kerja yang dicapai oleh seseorang atau sekelompok dosen dan karyawan dalam suau organisasi sesuai dengan peranya dalam institusi.

\section{METODE}

Penelitian ini menggunakan desain yang menggabungkan jenis penelitian kuantitatif dan kualitatif. Penggabungan kedua jenis penelitian ini dilakukan agar diperoleh data yang holistik sehingga diperoleh kesimpulan yang kuat dalam pengambilan kebijakan dan menentukan arah strategi yang diambil. Desain penelitian yang dilakukan dalam penelitian ini ada tiga yaitu 1) desain penelitian deskriptif-kualitatif, 2) desain penelitian survey dan 3) desain penelitian evaluasi CIPP. Desain penelitian deskriptif-kualitatif yaitu penelitian yang mengarah kepada pengungkapan suatu masalah atau keadaan sebagaimana adanya dan mengungkap fakta-fakta yang ada. Hasil penelitiannya difokuskan untuk memberikan gambaran keadaan dari objek yang diteliti.

Desain penelitian deskriptif-kualitatif akan digunakan untuk menganalisa dampak program Baitul Arqam terhadap penerapan nilai-nilai akhlak Dosen dan karyawan yang telah mengikuti kegiatan Baitul Arqam. Dari desain ini akan diperoleh data primer hasil dari observasi partisipan dan wawancara, serta data dokumentasi. Data yang telah terkumpul dalam tahap pengumpulan data, perlu dilihat terlebih dahulu, apabila belum lengkap maka perlu untuk dilengkapi. Tujuan untuk pengelolaan data adalah untuk menyederhanakan seluruh data yang terkumpul dan menyajikan data dalam susunan yang rapi dan baik. Teknik analisis data yang digunakan dalam penelitian ini adalah analisis data interaktif model Miles dan Huberman. Model ini terdiri dari tigal hal utama yaitu reduksi data, penyajian data, dan penarikan kesimpulan Miles et al. (2005). Tiga jenis kegiatan analisis dan kegiatan pengumpulan data merupakan proses siklus dan interaktif. Prosesnya digambarkan sebagai berikut.

[Figure 1 about here.]

Adapun Subjek dalam penelitian deskriptif kualitatif ini adalah informan yang dipilih dari kalangan dosen dan karyawan dilingkungan Kampus STKIP dan STIH Muhammadiyah Kotabumi. Survey adalah metode riset dengan menggunakan kuesioner sebagai instrumen pengumpulan datanya. Tujuannya untuk memperoleh informasi tentang sejumlah responden yang dianggap mewakili populasi tertentu Kriyantoro (2008). Desain Penelitian survey digunakan untuk melihat dampak Baitul Arqam terhadap kinerja Dosen dan karyawan di Lingkungan STKIP dan STIH Muhammadiyah Kotabumi. Pengukuran kinerja akan dilakukan dengan melihat kepuasan mahasiswa terhadap kinerja dosen dan karyawan. Instrumen yang digunakan berupa angket kepuasan mahasiswa terhadap kinerja dosen dan karyawan. Adapun subjek yang dikenai survey adalah seluruh Dosen dan karyawan yang telah mengikuti program Baitul Arqam. Selain itu kinerja juga akan diukur dengan melihat kedisiplinan dosen dan karyawan dan prestasi kerja.

Desain penelitian evaluasi CIPP dilakukan untuk mengevaluasi kegiatan Baitul Arqam. Desain penelitian model evaluasi CIPP digambarkan pada Gambar 3 berikut.

[Figure 2 about here.]

Adapun yang menjadi subjek penelitian evaluasi ini adalah semua unsur yang terlibat dalam program baitul Arqam yaitu: 1) Pihak Pimpinan, 2) Panitia Pelaksana, 3) Instruktur Program Baitul Arqam, 4) Peserta Baitul Arqam.

\section{HASIL DAN PEMBAHASAN}

\section{Persiapan Instrumen}

Instrumen yang digunakan berupa angket yang digunakan untuk mengukur nilai-nilai akhlak dan kinerja dosen dan karyawan. Angket ini dikembangkan dengan mengkaji berbagai referensi terkait nilai-nilai akhlak dan kinerja. Referensi dikumpulkan dari buku-buku dan artikel yang relevan. Pengumpulan sumber referensi dilaksanakan selama satu Minggu. Hasil penelaahan terhadap nilai-nilai akhlak, diperoleh beberapa butir indikator untuk mengukur nilai-nilai akhlak seorang dosen dan karyawan. Adapun indikator instrumen nilai-nilai akhlak disajikan dalam tabel berikut.

[Table 1 about here.]

Hasil penelaahan terhadap nilai-nilai akhlak, diperoleh beberapa butir indikator untuk mengukur nilai-nilai akhlak seorang dosen dan karyawan. Untuk indikator Kinerja Dosen dan Karyawan yaitu Disiplin Kerja, Kompetensi, Etos Kerja, Prestasi kerja, dan komunikasi.

\section{Pelaksanaan Penelitian}

Validasi Instrumen

Kegiatan validasi dilaksanakan mulai pada tanggal 24 Oktober 2019 sampai dengan selesai. Sebelum validasi instrumen dilaksanakan, instrumen ditelaah dahulu oleh tim peneliti. Instrumen telah didesain dan dirapikan agar mudah dalam membacanya. Instrumen angket nilai-nilai akhlak dosen dan karyawan dan instrumen angket kinerja dosen dan karyawan diberikan ke masing-masing dua Validator. Validator tersebut adalah Dr. Badawi, M.Pd., Dr. Sri Widayati, M.Hum., dan Salis M. Abduh, S.H., M.H..

Instrumen angket nilai-nilai akhlak dosen dan karyawan divalidasi oleh Dr. Badawi, M.Pd. dan Salis M. Abduh, S.H., M.H.. Dr. Badawi, M.Pd. merupakan orang yang sudah dipercaya di lingkungan Pimpinan Daerah Muhammadiyah Lampung Utara sebagai instruktur Baitul Arqom dan AIK. Salis M. Abduh, S.H., M.H. merupakan Kepala Pusat Pengembangan dan Pembelajaran Al Islam dan Kemuhammadiyahan (PPPAIK) di Universitas Muhammadiyah Kotabumi. 
Instrumen angket kinerja dosen dan karyawan divalidasi oleh Dr. Badawi, M.Pd. dan dan Dr. Sri Widayati, M.Hum.. Dr. Badawi, M.Pd. merupakan Wakil Ketua II Bidang Umum, Keuangan, dan Kepegawaian ketika di STKIP Muhammadiyah Kotabumi (sebelum bergabung menjadi Universitas Muhammadiyah Kotabumi). Dr. Sri Widayati, M.Hum. merupakan ketua Lembaga Penelitian dan Pengabdian pada Masyarakat (LPPM) di Universitas Muhammadiyah Kotabumi.

Hasill validasi menunjukan bahwa seluruh instrumen dapat dikategorikan layak untuk digunakan. Ada beberapa saran dan masukan yang diberikan oleh Validator mengenai kedua instrumen tersebut. Saran tersebut kita rangkum secara keseluruhan seperti: tampilan agar dibuat simpel dan rapi, kebahasaan ada beberapa yang tidak menggunakan bahasa baku, konsisten penggunaan istilah, dan butir/kalimat dalam angket dipermudah/diperbaiki agar lebih praktis.

\section{Analisis Data Hasil Penelitian}

Kegiatan analisis data hasil penelitian ini dilakukan setelah pengambilan data dilaksanakan, yaitu pengisian angket dan respons wawancara. Angket disebarkan kepada 42 Responden yang terdiri dari dosen dan karyawan di STKIP Muhammadiyah Kotabumi dan STIH Muhammadiyah Kotabumi. Berikut dipaparkan analisis hasil angket akhlak dan kinerja dosen dan karyawan. Analisis didukung oleh data hasil wawancara (data angket dan wawancara diasumsikan responden mengisi dan menjawab secara jujur).

- Analisis Data Nilai-nilai Akhlak Dosen dan Karyawan

Data nilai-nilai akhlak diklasifikasikan menjadi beberapa indikator. Indikator selanjutnyaditurunkan menjadi indikator kerja. Pengklasifikasian indikator nilai-nilai akhlak digunakan untuk mempermudah analisis sehingga mempertajam kesimpulan penelitian. Berikut paparan hasil analisis data setiap indikator nilai-nilai akhlak dosen dan karyawan.

\section{- Ibadah Shalat}

Pengukuran ibadah shalat dilaksanakan dengan tujuan untuk melihat apakah responden 1) melaksanakan ibadah shalat lima waktu tepat waktu, 2) melaksanakan sholat berjamaah, 3) mengerjakan shalat sunnah. Masing-masing tujuan diturunkan menjadi indikator kerja untuk indikator ibadah shalat. Data responden terkait dengan pelaksanaan shalat lima waktu secara tepat waktu, pelaksanaan sholat berjamaah, mengerjakan shalat sunnah disajikan dalam grafik berikut.

[Figure 3 about here.]

Berdasarkan Grafik, dapat dikatakan bahwa mayoritas responden telah melaksanakan shalat wajib lima waktu secara tepat waktu dan berjamaah. Tetapi masih ada responden yang jarang dan tidak pernah shalat sunnah. Peneliti melakukan wawancara terhadap perwakilan responden dan mendapatkan jawaban bahwa responden jarang atau tidak pernah melaksanakan shalat sunnah dikarena kurangnya kesadaran akan pentingnya shalat sunnah, serta kurang paham akan besarnya pahala yang diperoleh jika melaksanakan shalat sunnah.
- Ibadah Puasa, Amanah, Syukur, dan Tawakal

Data Penelitian terkait ibadah puasa, amanah, syukur, dan tawakal disajikan dalam grafik berikut.

\section{[Figure 4 about here.]}

Berdasarkan grafik, hampir semua responden memiliki ibadah puasa, amanah, syukur, dan tawakal yang sangat baik dan baik.

- Jujur, Ikhlas, Kasih Sayang, dan Penolong

Data Penelitian terkait ibadah Jujur, Ikhlas, Kasih Sayang, dan penolong disajikan dalam grafik berikut.

[Figure 5 about here.]

Berdasarkan grafik, hampir semua responden memiliki ibadah Jujur, Ikhlas, Kasih Sayang, dan penolong yang sangat baik dan baik.

Adil, Disiplin, Toleransi, dan akhlaq terhadap lingkungan

Data Penelitian terkait adil, disiplin, toleransi dan akhlaq terhadap lingkungan disajikan dalam grafik berikut.

[Figure 6 about here.]

Berdasarkan grafik, hampir semua responden memiliki Adil, disiplin, toleransi, dan akhlak terhadap lingkungan yang sangat baik dan baik.

\section{Analisis Data Kinerja Dosen dan karyawan}

Data kinerja dosen dan karyawan diklasifikasikan menjadi beberapa indikator. Pengklasifikasian indikator kinerja dosen dan karyawan digunakan untuk mempermudah analisis sehingga mempertajam kesimpulan penelitian. Berikut paparan hasil analisis data setiap indikator kinerja dosen dan karyawan dosen dan karyawan.

[Figure 7 about here.]

Berdasarkan grafik, hampir semua responden memiliki Disiplin kerja, Kompetensi kerja, Etos Kerja, Prestasi kerja, dan Komunikasi, yang sangat baik dan baik.

\section{Evaluasi Kegiatan Baitul Arqam}

Evaluasi kegiatan baitul arqam didasarkan pada data pengamatan peneliti sekaligus merupakan panitia kegiatan baitul arqam, data hasil angket dan wawancara dosen dan karyawan di universitas muhammadiyah kotabumi yang telah mengikuti kegiatan baitul arqam. Adapun metode yang digunakan untuk mengevaluasi kegiatan baitul arqam disajikan dalam gamber berikut.

Berikut dipaparkan hasil evaluasi kegiatan baitul Arqam di Universitas Muhammadiyah Kotabumi.

Evaluasi Context

Ada 2 hal yang akan dilihat dalam tahap context yaitu

1. Kesesuaian program dengan Analisis kebutuhan Institusi dan masyarakat. 
Hasil evaluasi context menunjukan adanya kesesuaian program baitul arqam dengan kebutuhan institusi dan masyarakat. Kesimpulan ini didukung oleh data hasil survei dan wawancara responden yang berasal dari dosen dan karyawan Universitas Muhammadiyah Kotabumi yang telah mengikuti program baitul arqam. Universitas muhammadiyah kotabumi tentu saja sangat mengharapkan adanya dosen dan karywan yang memiliki akhlak yang baik serta kinerja yang baik pula. Berdasarkan hasil survei mayoritas responden memiliki akhlak yang baik dan kinerja yang baik pula.

2. Kesesuaian Tujuan dan Sasaran Program dengan Visi, misi dan tujuan Insitusi.

Universitas Muhammadiyah Kotabumi memiliki visi pada tahun 2038 menjadi kampus technopreuneurship, islami dan unggul berbasis kearifan lokal. Untuk mewujudkan visi tersebut tentu saja sangat memerlukan sumber daya manusia yang berkualitas. Nilai-nilai akhlak yang tertanam baik serta memilki kinerja yang baik merupakan suatu indikator untuk melihat kualitas sumber daya manusia. Oleh karena itu, program baitul arqam sangat sesuai dengan kebutuhan institusi guna mewujudkan visi-misinya.

Dengan demikian, 2 hal yang ada dalam tahap context yaitu kesesuaian program dengan Analisis kebutuhan Institusi dan masyarakat dan Kesesuaian Tujuan dan Sasaran Program dengan Visi, misi dan tujuan Insitusi berdasarkan hasil evaluasi pada aspek context dapat dikategorikan baik sekali. Hasil Evaluasi context disajikan dalam Tabel

[Table 2 about here.]

Evaluasi Input

Pembahasan evaluasi input mencakup lima komponen yaitu; materi sumber daya manusia, sarana dan Prasaran, dana dan metode. Penjelasan evaluasi input dijelaskan dalam matriks berikut.

[Table 3 about here.]

Evaluasi Proses

Pembahasan evaluasi proses mencakup tiga komponen yaitu: jadwal, aktivitas dan monitoring serta evaluasi. Penjelasan evaluasi input dijelaskan dalam matriks berikut.

[Table 4 about here.]

Evaluasi Product

Pembahasan evaluasi product hanya mencakup jumlah minimal kehadiran Bagi Karyawan dalam bidang Al-Islam dan Kemuhammadiyahan baik secara teori maupun praktek. Lulus disini memenuhi syarat nilai kehadiran lebih dari $75 \%$ pada setiap sesi materi. Namun ada sebagian peserta yang dinyatakan lulus ini. Berdasarkan hasil evaluasi produk, sebaiknya persyaratan wajib peserta dinyatakan lulus jika mengikut fathul quthub dan shalat tahajud, serta mengikuti materi setiap sesi minimal 75\%. Berdasarkan hasil analisis data hasil penelitian dan hasil evaluasi context, Proses, metode, dan product diperoleh kesimpulan sebagai berikut:

\section{KESIMPULAN}

Berdasarkan hasil analisis data hasil penelitian dan hasil evaluasi context, Proses, metode, dan product diperoleh kesimpulan sebagai berikut:

1. Berdasarkan hasil analisis data hasil angket dan wawancara dapat disimpulkan bahwa Dosen dan karyawan yang telah mengikuti kegiatan baitul Arqam memiliki akhlak yang baik dan kinerja yang tinggi.

2. Berdasarkan hasil Evaluasi dapat disimpulkan bahwa; Evaluasi Input

- Materi baitul arqam sebaiknya dijadikan dalam satu buku dan di distribusikan ke peserta

- Materi sebaiknya juga membahas terkait ibadah shalat, penyelenggaraan jenazah, dan ibadah yang lain yang sesuai dengan tuntunan HPT.

- Adanya video pembelajaran yang menarik sehingga peserta lebih tertarik dan fokus.

- Setiap dosen dan karyawan yang belum mengikuti baitul arqam harus mengikuti kegiatan tersebut.

- Adanya prestest dan postest untuk mengukur keberhasilan peserta.

- Evaluasi setiap selesainya kegiatan baitul arqam harus dilaksanakan, sebagai pertanggungjawaban panitia dan sebagai bahan evaluasi kegiatan baitul arqam yang akan datang

\section{Evaluasi Proses}

- Pelaksanaan baitul arqam sebaiknya dilaksanakan di kampus.

1. peserta Baitul Arqam diberikan kebijakan dibebaskan dari jabatan struktural dalam memberikan pelayanan kepada mahasiswa dan lainnya. Hasil ini didukung dengan data wawancara $>90 \%$ peserta ingin fokus mengikuti kegiatan, berharap ada surat tugas khusus sehingga tidak dibebani hal lain di bidang structural

Evaluasi Product

persyaratan wajib peserta dinyatakan lulus jika mengikut fathul quthub dan shalat tahajud, serta mengikuti materi setiap sesi minimal $75 \%$

\section{UCAPAN TERIMA KASIH}

Kami Mengucapkan terimakasih yang sebesar-besarnya kepada Majelis diktilitbang yang telah mendanai penelitian ini. Kami juga mengucapkan terimakasih kepada Rektor Universitas Muhammadiyah Kotabumi, Kepala LPPM, Kepala PPPAIK, dan kepada Responden yang berasal dari dosen dan karyawan dilingkungan Universitas Muhammadiyah Kotabumi. 


\section{REFERENCES}

Anshori, A. (2017). Dinamisasi Perkaderan Muhammadiyah (Yogyakarta: MPK PP Muhammadiyah).

Arifin, F., Haming, M., Ramlawati, and Lamo, M. (2015). Merging Paramedic Performance And Service Quality. An Empirical Test Of An Integrative Model. International Journal of Business and Management 4, 52-58.

Hamzah, Y. (1998). Etika Islam Pembinaan Akhlaqulkarimah (Bandung: CV. Diponegoro).

Kartini, N. H. (2017). Evaluasi Program Baitul Arqam bagi Karyawan di Universitas Muhammadiyah Palangkaraya. Anterior Jurnal 16, 144-157.

Kriyantoro, R. (2008). Teknik Praktis riset Komunikasi (Jakarta: Kencana Prenada Media Grup).

Miles, M. B., Michael, A., , and Huberman (2005). Qualitative Data Analisis (terjemahan) (Jakarta: UI Press).

Mustofa (2005). Akhlak Tasawuf (Bandung: CV Pustaka Setia).

Nursikin, M. (2019). Implementasi Nilai-Nilai Akhlak terhadap Dosen Kesehatan dalam Prespektif Islam di Akademi Kebidanan Yogyakarta. Istawa: Jurnal Pendidikan Islam (IJPI) 3, 25-56. doi: 10.24269/ijpi.v3i2.1500.

Yunahar (1999). Kuliah Akhlak (Yogyakarta: Lembaga Pengkajian dan Pengalaman Islam).

Conflict of Interest Statement: The authors declare that the research was conducted in the absence of any commercial or financial relationships that could be construed as a potential conflict of interest.

Copyright (C) 2020 Junaidi, Dinata and Darwanto. This is an open-access article distributed under the terms of the Creative Commons Attribution License (CC BY). The use, distribution or reproduction in other forums is permitted, provided the original author(s) and the copyright owner(s) are credited and that the original publication in this journal is cited, in accordance with accepted academic practice. No use, distribution or reproduction is permitted which does not comply with these terms. 


\section{LIST OF TABLES}

1 Indikator nilai-nilaiakhlak ... . . . . . . . . . . . . . . . . . . . . . . . 142

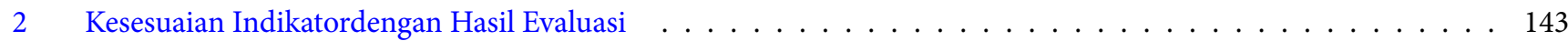

3 Matriks Evaluasi Input . . . . . . . . . . . . . . . . . . . . . . . . . . . . . . . . . . . . . 144

4 Matriks Evaluasi Proses . . . . . . . . . . . . . . . . . . . . . . . . . . . . 145 
TABLE 1 | Indikator nilai-nilaiakhlak

\begin{tabular}{|c|c|c|}
\hline No & Dimensi & Indikator \\
\hline & Akhlak Kepada Allah & Ibadah shalat, puasa, taubat, ikhlas, bersyukur, tawakal \\
\hline \multicolumn{3}{|l|}{ 1. 1} \\
\hline 1. 2. & Akhlak kepada Rasullah & $\begin{array}{l}\text { Sidiq (jujur), amanah (terpercaya), patonah (cerdas), tablig (menyam- } \\
\text { paikan) }\end{array}$ \\
\hline 1. 3. & Akhlak kepada sesama manusia & $\begin{array}{l}\text { Jujur, ikhlas, amanah, tawadhu, sabar, kasih sayang, pemaaf, penolong, } \\
\text { berani, adil, rajin, disiplin, kreatif, sederhana, baik sangka, dermawan, } \\
\text { toleransi, berbakti kepada orang tua, iffah. }\end{array}$ \\
\hline 1. 4. & Akhlak kepada lingkungan & $\begin{array}{l}\text { Menjaga tumbuh-tumbuhan, menyanyangi hewan, memelihara kebersi- } \\
\text { han, memelihara ketenteraman. }\end{array}$ \\
\hline
\end{tabular}


TABLE 2 | Kesesuaian Indikatordengan Hasil Evaluasi

\begin{tabular}{lll}
\hline No & Indikator & Hasil Evaluasi \\
1 & Kesesuaian program dengan Analisis kebutuhan Institusi dan masyarakat & Sesuai \\
2 & Kesesuaian Tujuan dan Sasaran Program dengan Visi, misi dan tujuan Insitusi. & Sesuai
\end{tabular}

Kesesuaian Tujuan dan Sasaran Program dengan Visi, misi dan tujuan Insitusi.

Sesuai 
TABLE 3 | Matriks Evaluasi Input

No Komponen

$1 \quad$ Materi

\section{Sumber Daya Manusia}

3

4

5

Sarana dan Prasarana
Hasil Evaluasi

1. Materi Baitul arqam belum terdokumentasi dengan baik dalam satu buku

2. Berdasarkan hasil wawancara peserta lebih tertarik dengan materi penyelenggaraan jenazah mulai dari memandikan, mengkafani sampai menshalatkan. Sedangkan materi yang sulit dipahami, hanya sebagian kecil peserta yang menjawab.

3. Materi pembelajaran masih monoton sehingga beberapa peserta mengantuk atau tidak fokus

1. Pemateri dari kegiatan baitul arqam berasal dari PWM yang cukup kompeten

2. Peserta berasal dari dosen dan karyawan UMKO yang belum mengikuti baitul arqam

1. Sarana dan prasarana sudah sangat mendukung pelak sanaan program Baitul Arqam Bagi Karyawan. Prasarana seperti masjid kampus Universitas Muhammadiyah Kotabumi, sangat mendukung proses pembimbingan. Terkait ketersediaan sarana, adanya LCD yang terpasang didalam aula, sangat membantu proses pembelajaran

1. Mengingat bahwa kesiapan dan implementasi program yang berjalan sudah berhasil, sehingga dukungan danapun mengalir dengan lancar

Metode pembelajaran yang digunakan sudah sesuai dalam pencapaian pembelajaran dan diselingi dengan out bond agar peserta tetap fokus
Saran

1. Materi baitul arqam sebaiknya dijadikan dalam satu buku dan di distribusikan ke peserta

2. Materi sebaiknya juga membahas terkait ibadah shalat, penyelenggaraan jenazah, dan ibadah yang lain yang sesuai dengan tuntunan HPT.

3. Adanya video pembelajaran yang menarik sehingga peserta lebih tertarik dan fokus.

1. Pemateri akan lebih menarik mendatangkan dari Pimpinan Pusat.

2. Setiap dosen dan karyawan yang belum mengikuti baitul arqam harus mengikuti kegiatan tersebut.

1. Berdasarkan hasil evaluasi sarana dan Prasarana, baitul arqam selanjutnya sebaiknya tetap diadakan di dalam kampus UMKO.

Komitmen dalam penyediaan dana untuk kegiatan baitu arqam oleh pimpinan harus selalu dijaga

Metode pembelajaran harus dipertahankan dan variasi out bond harus diperbanyak 
TABLE 4 | Matriks Evaluasi Proses

\begin{tabular}{|c|c|c|c|}
\hline No & Aspek & Hasil evaluasi & Saran \\
\hline 1 & Jadwal & $\begin{array}{l}\text { 1. Peserta menyebutkan pelaksanaan Baitul } \\
\text { arqam sebaiknya dilaksanakan di kampus, tetapi } \\
\text { berdasarkan hasil pengamatan banyak peserta yang } \\
\text { pulang, tidak ikut shalat tahajud di kampus, tidak } \\
\text { mengikuti fathul quthub, dan tidak disiplin dalam } \\
\text { mengikuti acara } \\
\text { 2. Tidak ada lagi kebijakan selama Baitul Arqam, } \\
\text { pelayanan struktural diliburkan, sehingga ada beber- } \\
\text { apa peserta yang absen di satu atau dua materi } \\
\text { sesi Baitul Arqam. Karena sebagian besar karyawan } \\
\text { yang mengikuti kelopok dasar dan lanjutan ditahun } \\
\text { berjalan tersebut merangkap sebagai dosen, jadi } \\
\text { kalau ada jadwal ujian skripsi atau praktikum maka } \\
\text { peserta sedikit kebingungan membagi waktu. }\end{array}$ & $\begin{array}{l}\text { 1. Pelaksanaan baitul arqam sebaiknya dilaksanakan } \\
\text { di kampus. } \\
\text { 2. peserta Baitul Arqam diberikan kebijakan } \\
\text { dibebaskan dari jabatan struktural dalam mem- } \\
\text { berikan pelayanan kepada mahasiswa dan lainnya. } \\
\text { Hasil ini didukung dengan data wawancara }>90 \% \\
\text { peserta ingin fokus mengikuti kegiatan, berharap } \\
\text { ada surat tugas khusus sehingga tidak dibebani hal } \\
\text { lain di bidang struktural }\end{array}$ \\
\hline 2 & Aktifitas Pembelajaran & $\begin{array}{l}\text { komponen aktifitas pembelajaran sudah berjalan } \\
\text { dengan baik sesuai yang ditentukan, sehingga aspek } \\
\text { ini tergolong pada kategori baik. }\end{array}$ & - \\
\hline 3 & Monitoring dan Evaluasi & $\begin{array}{l}\text { 1. Monitoring peserta baitul arqam masih sebatas } \\
\text { jumlah kehadiran. } \\
\text { 2. Evaluasi Kegiatan baitul arqam tidak berjalan }\end{array}$ & $\begin{array}{l}\text { 1. Adanya prestest dan postest untuk mengukur } \\
\text { keberhasilan peserta. } \\
\text { 2. Evaluasi setiap selesainya kegiatan baitul arqam } \\
\text { harus dilaksanakan, sebagai pertanggungjawaban } \\
\text { panitia dan sebagai bahan evaluasi kegiatan baitul } \\
\text { arqam yang akan datang }\end{array}$ \\
\hline
\end{tabular}




\section{LIST OF FIGURES}

1 Komponen-komponen Analisis Data Model interaktif . . . . . . . . . . . . . . . . . . . . . . . 147

2 Desain penelitian model evaluasi CIPP . . . . . . . . . . . . . . . . . . . . . . . 148

3 Grafik terkait dengan pelaksanaan shalat lima waktu secara tepatwaktu, pelaksanaan sholat berjamaah, mengerjakan shalat sunnah disajikan . . . . . . . . . . . . . . . . . . . . . . . . . . 149

4 Grafik terkait ibadah puasa, amanah, syukur, dantawakal . . . . . . . . . . . . . . . . . . . . . . . . . . . . . .

5 Grafik terkait ibadah Jujur, Ikhlas, Kasih Sayang, danpenolong . . . . . . . . . . . . . . . . . . . . . . 151

6 Grafik terkait adil, disiplin, toleransi dan akhlaqterhadap lingkungan . . . . . . . . . . . . . . . . . . . . . . . . . .

7 Grafik Kinerja Dosen dankaryawan . . . . . . . . . . . . . . . . . . . . . . . 153 


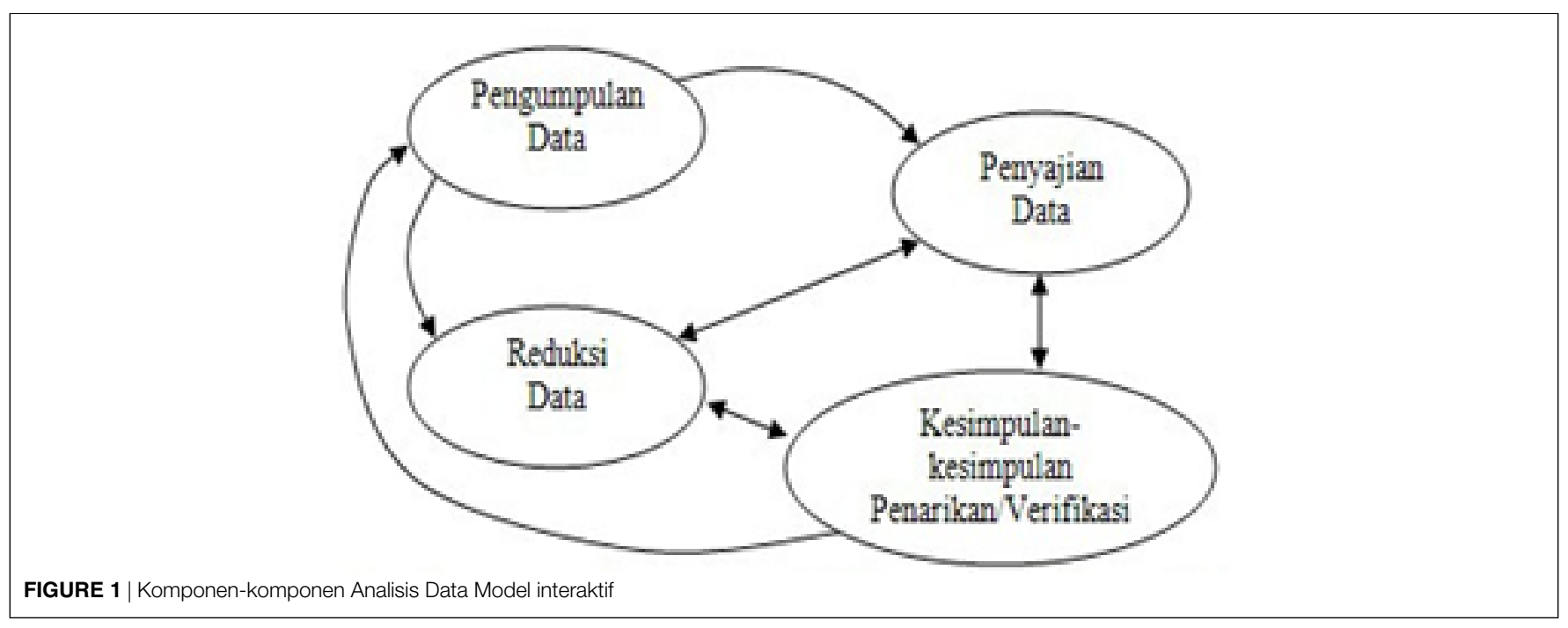



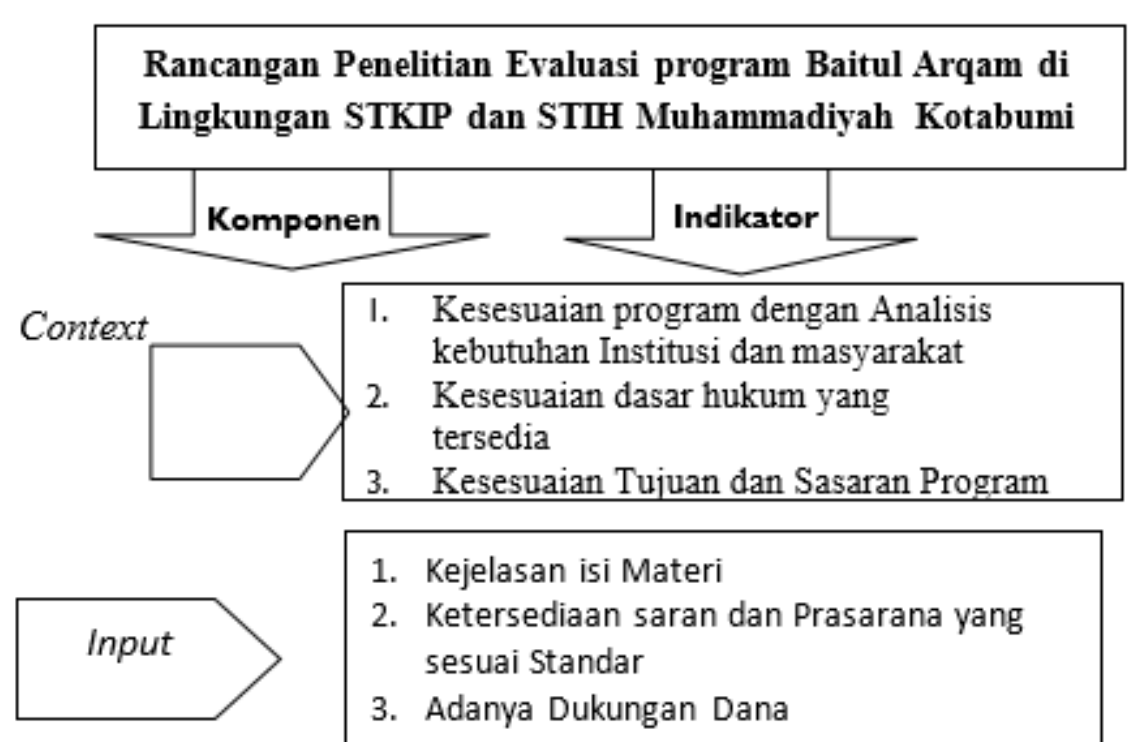

1. Kejelasan isi Materi

2. Ketersediaan saran dan Prasarana yang sesuai Standar

3. Adanya Dukungan Dana

4. Adanya Metode bervariasi dan Inovatif

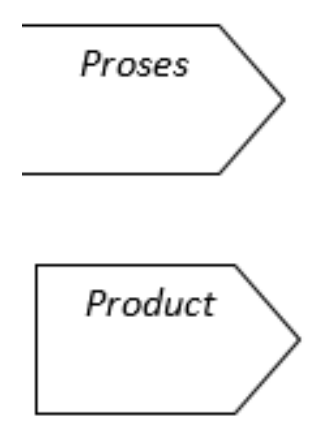

1. Tersedianya Jadwal Pelaksanaan Baitul Arqam

2. Pelaksanaan Aktifitas

3. Adanya Monev terbatas

Peserta Baitul Arqam memiliki Kompetensi dalam Pemahaman keislaman dan kemuhammadiyahan.

FIGURE 2 | Desain penelitian model evaluasi CIPP 


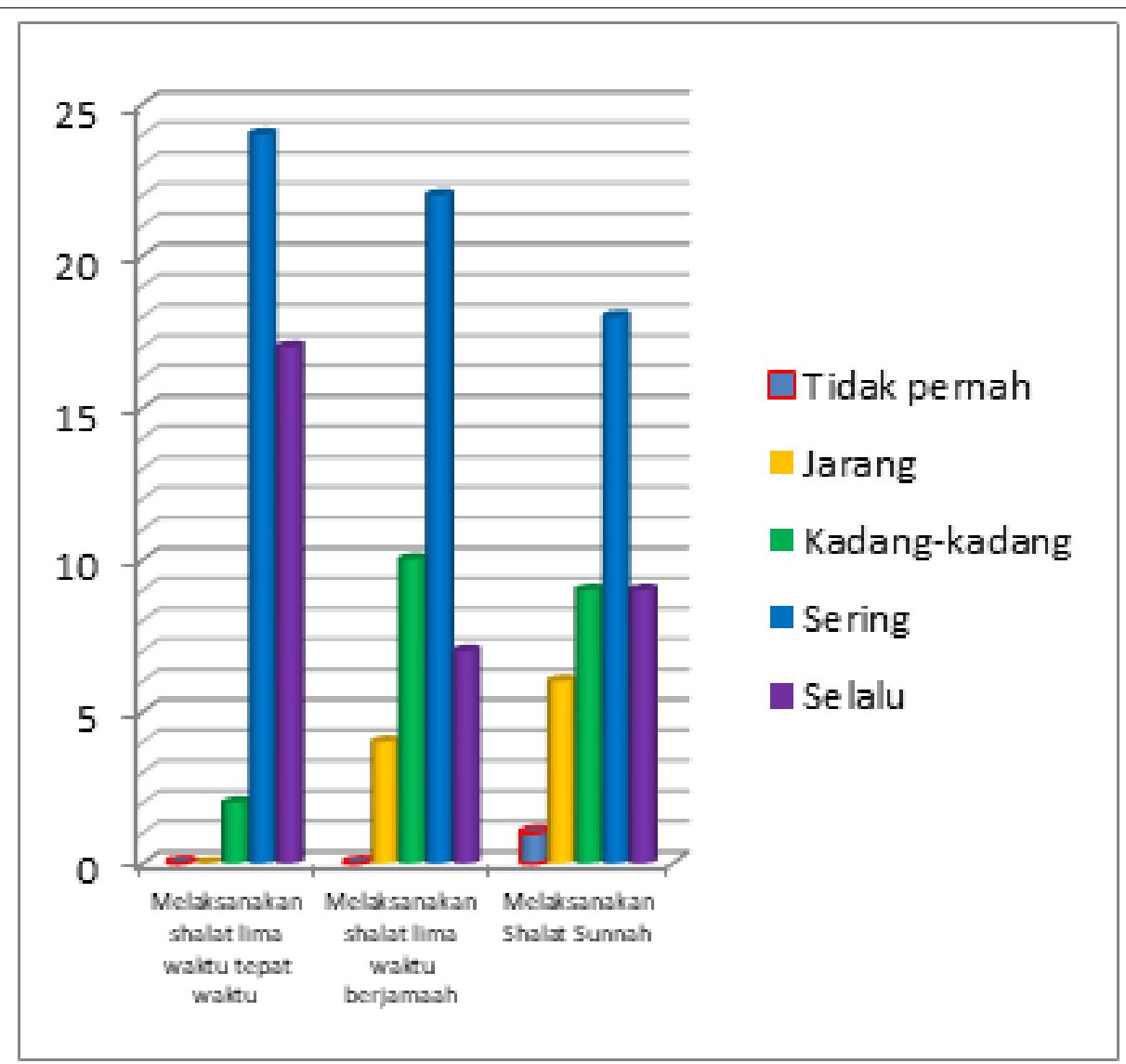

FIGURE 3 | Grafik terkait dengan pelaksanaan shalat lima waktu secara tepatwaktu, pelaksanaan sholat berjamaah, mengerjakan shalat sunnah disajikan 


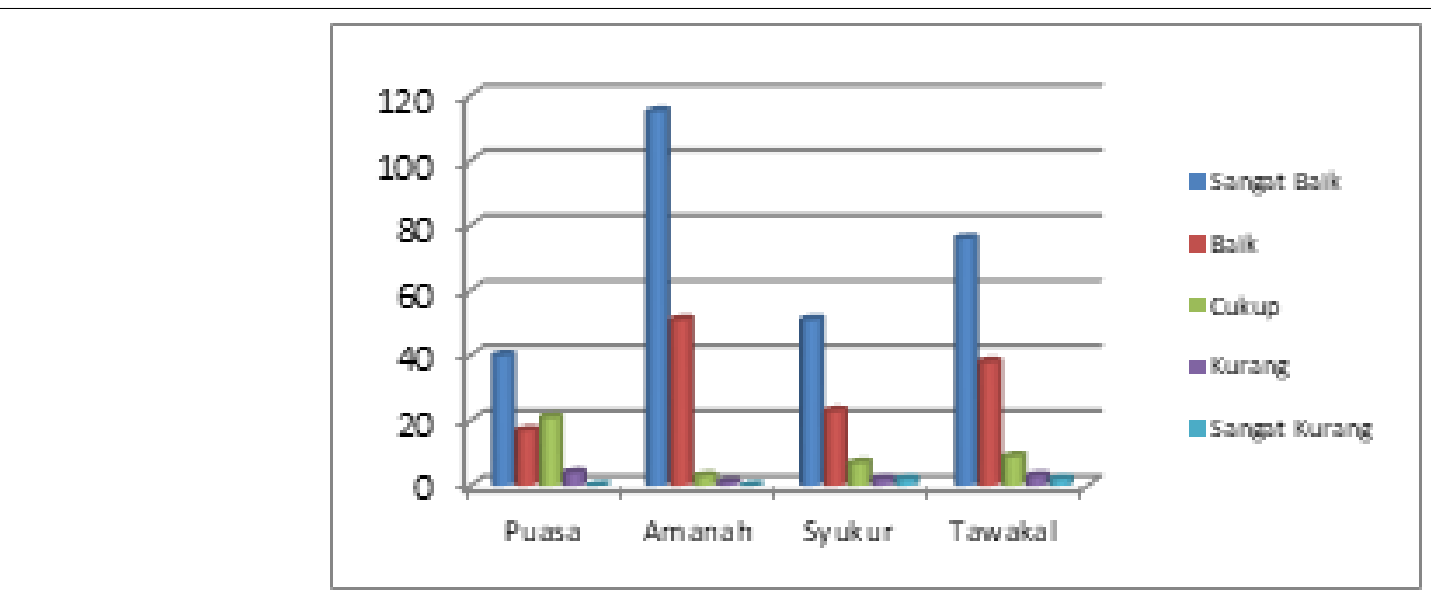

FIGURE 4 | Grafik terkait ibadah puasa, amanah, syukur, dantawakal 


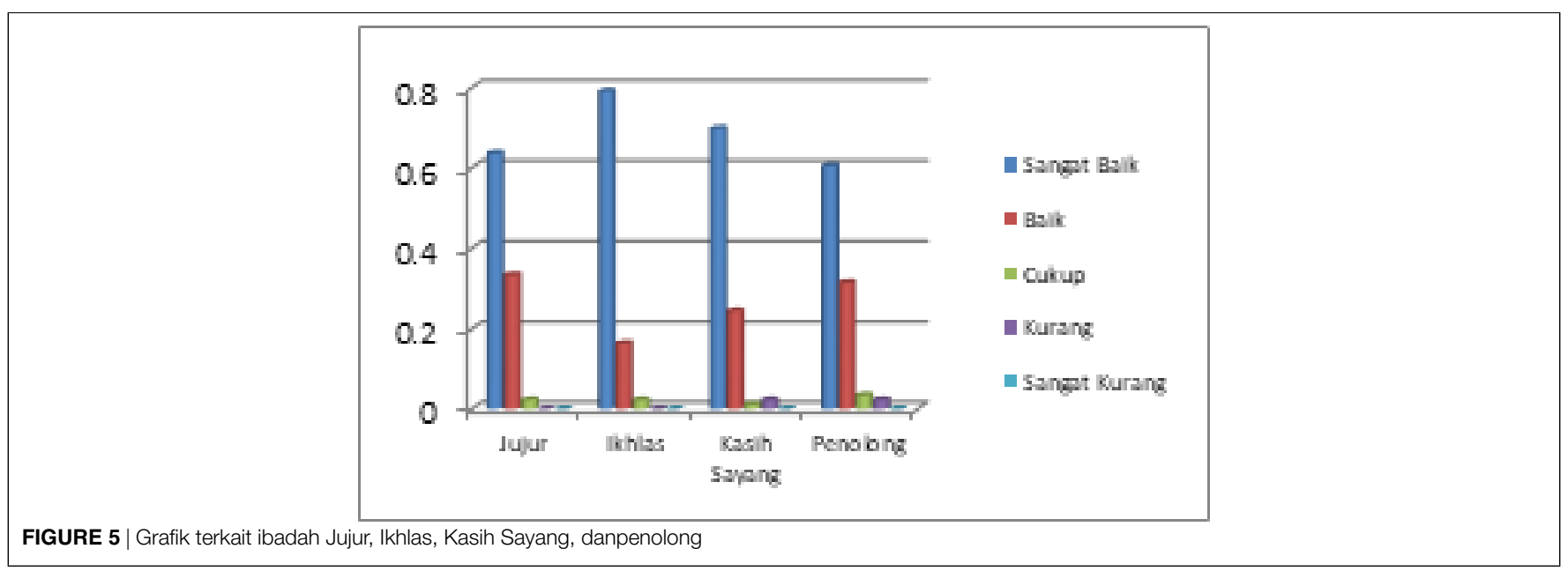




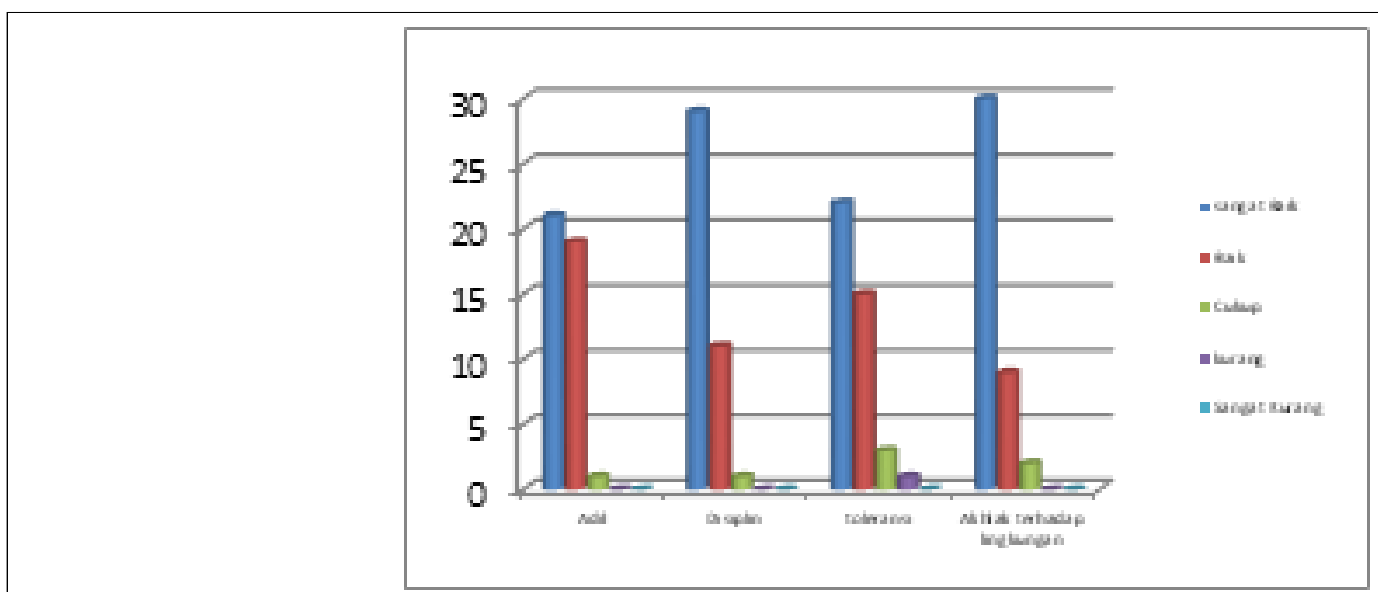

FIGURE 6 | Grafik terkait adil, disiplin, toleransi dan akhlaqterhadap lingkungan 


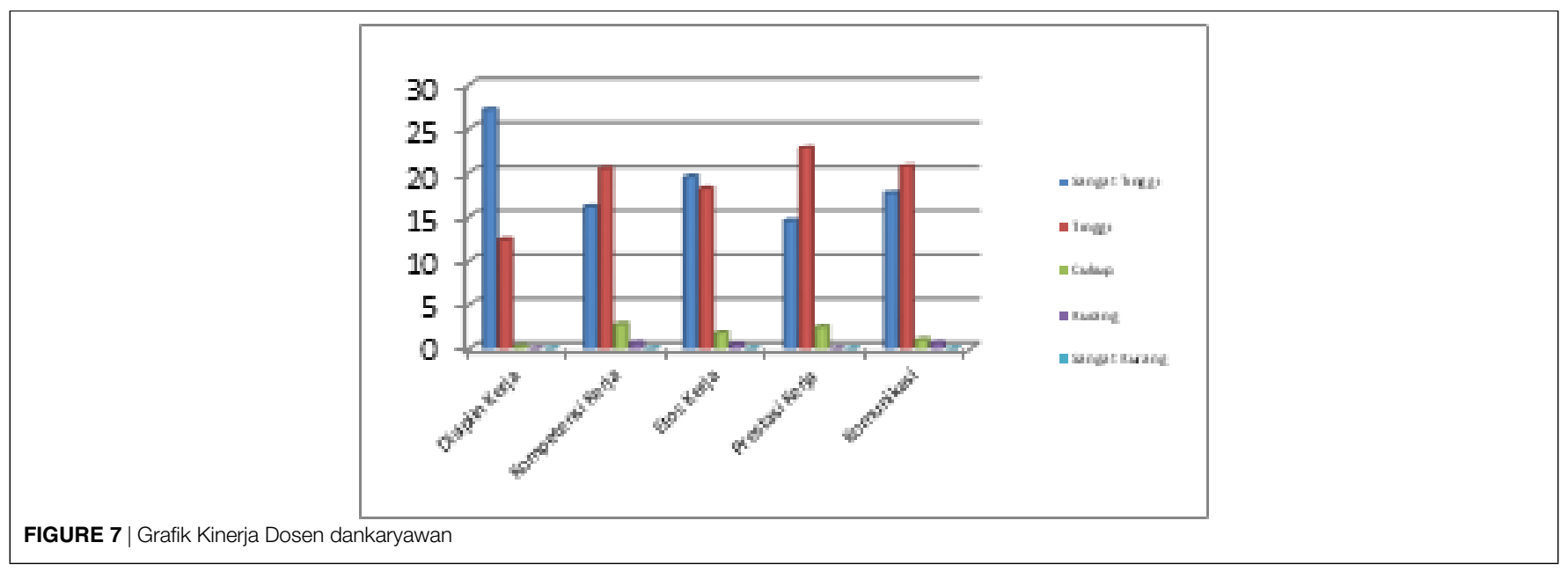

